\title{
Discharge Coefficient Measurements for Flow Through Compound-Angle Conical Holes with Cross-Flow
}

\author{
M. E. Taslim* and S. Ugarte \\ Mechanical, Industrial and Manufacturing Engineering Department, Northeastern University, \\ Boston, MA 02115, USA
}

Diffusion-shaped film holes with compound angles are currently being investigated for high temperature gas turbine airfoil film cooling. An accurate prediction of the coolant blowing rate through these film holes is essential in determining the film effectiveness. Therefore, the discharge coefficients associated with these film holes for a range of hole pressure ratios is essential in designing airfoil cooling circuits. Most of the available discharge coefficient data in open literature has been for cylindrical holes. The main objective of this experimental investigation was to measure the discharge coefficients for subsonic as well as supersonic pressure ratios through a single conical-diffusion hole. The conical hole has an exit-to-inlet area ratio of 4 , a nominal flow length-to-inlet diameter ratio of 4 , and an angle with respect to the exit plane (inclination angle) of $0^{\circ}, 30^{\circ}, 45^{\circ}$, and $60^{\circ}$. Measurements were performed with and without a crossflow. For the cases with a cross-flow, discharge coefficients were measured for each of the hole geometries and 5 angles between the projected conical hole axis and the cross-flow direction of $0^{\circ}, 4^{\circ}, 90^{\circ}, 135^{\circ}$, and $180^{\circ}$. Results are compared with available data in open literature for cylindrical film holes as well as limited data for conical film holes.

Keywords Discharge coefficient, Shaped film holes, Compoundangle film holes, Conical film holes

\section{INTRODUCTION}

Diffusion-shaped holes are commonly used in film cooling of the gas turbine airfoils. The purpose for employing such holes is to reduce the coolant velocity at the film hole exit in order to

Received 10 October 2003; in final form 10 October 2003.

*Corresponding author. Tel.: (617)373-5514, Fax: (617)373-2921. E-mail:m.taslim@neu.edu sustain film effectiveness over a range of blowing ratios, i.e., to allow for required higher rate of coolant before exit jet lift-off occurrence and to enhance the lateral spreading of the coolant over the airfoil downstream surface. The conical holes can be produced by laser drilling or spark erosion method. Influenced by several factors, these film holes are often drilled at a compound angle that further complicates the film hole geometry. Given that proper cooling of the airfoil with the least amount of coolant is the ultimate goal of the blade design engineer, an accurate assessment of the coolant flowing through the film holes is imperative. This task is best accomplished by using the discharge coefficient associated with these film hole geometries as a function of flow parameters on both sides of the film holes.

Discharge coefficients associated with many orifice geometries and flow conditions have been under investigation by many researchers. These investigators include Rohde et al. (1969) who performed an experimental study of discharge coefficients for flow through thick plate orifices with the approaching flow perpendicular or inclined to the orifice axis. Meitner and Hippensteele (1977) performed an experimental study on the discharge coefficient of impingement holes in a full-coverage, film-cooled vane chamber. Hippensteele and Cochran (1980) studied the effect of hole geometry and electric discharge machining on airflow rates through small diameter holes in turbine blade materials. Hay et al. (1983) reported on the effect of crossflows on the discharge coefficient of cylindrical holes at inclination angles of $30^{\circ}, 60^{\circ}$, and $90^{\circ}$. Parker and Kercher (1991) introduced an enhanced method to compute the compressible discharge coefficient of thin and long orifices with inlet corner radiusing based on the presented data in open literature. This method accounts for compressibility, inlet corner radius, orifice length, and Reynolds number. Hay and Spencer (1992) investigated the effects of radiused and chamfered inlets on the discharge coefficients of straight-through cylindrical cooling holes. They concluded that inlet radiusing and chamfering increases the discharge coefficient substantially. Hay et al. (1994) measured 
the discharge coefficients for $30^{\circ}$ inclined cylindrical holes with rounded inlet and exit and a range of cross-flows on both sides of the holes. A major conclusion of this study was that while inlet radiusing was beneficial, rounding of the exit did not produce any significant benefit. Hay and Lampard (1995) reported on the discharge coefficient for $90^{\circ}$ and $30^{\circ}$ flared film-cooling holes with a cylindrical inlet portion for the effects of the length of the cylindrical portion, effects of the deletion of the layback of the hole flare, effects of cross-flow on the inlet and on the outlet of the hole, and effects of the orientation of the cross-flow relative to the axial direction of the hole. Among their major conclusions were that discharge coefficients for the flared holes is higher than that for cylindrical holes, and external cross-flow up to a Mach number of 0.3 does not affect the discharge coefficient while internal cross-flow reduces the discharge coefficient, particularly at pressure ratios less than 1.3. Burd and Simon (1998) measured the discharge coefficients for a row of 11 cylindrical holes with $35^{\circ}$ inclination for $\mathrm{L} / \mathrm{d}$ ratios of $2.3,4.6,6.6$, and 7.0 with and without the presence of a freestream flow. Film injection to the freestream flow was both steamwise and lateral. They concluded that shorter film cooling holes have higher discharge coefficient values due to interaction with freestream flow.
The present investigation deals with conical holes of different compound angles that are fed from a high pressure plenum and are vented either to a low pressure plenum (lab) or to a channel with a Mach number of 0.075 or 0.128 . The conical hole results are compared with those of a straight-through cylindrical hole of the same diameter which served as the baseline. Length-to-inlet diameter ratio varies from 2.54 to 3.71 . Exit-to-inlet area ratio along the centerline for the conical holes varies from 2.63 to 3.65 .

\section{TEST FACILITY}

Figure 1a shows the schematics of the test assembly and hole geometry tested. The experimental setup consisted of two separate air circuits. The main circuit fed the low-pressure crossflow channel while the secondary circuit supplied air to the highpressure plenum that fed the conical hole. The main components of the apparatus were a rotatable high-pressure plenum to allow the testing of several jet angles with cross-flow, a detachable orifice plate to allow the testing of several hole geometries, and a fixed, low-pressure cross-flow channel with its own plenum to allow for the investigation of cross-flow effects on the discharge coefficient. The high-pressure plenum was a cylindrical pipe of $12.7 \mathrm{~cm}$ diameter with a length of $30.5 \mathrm{~cm}$ and flanges on both

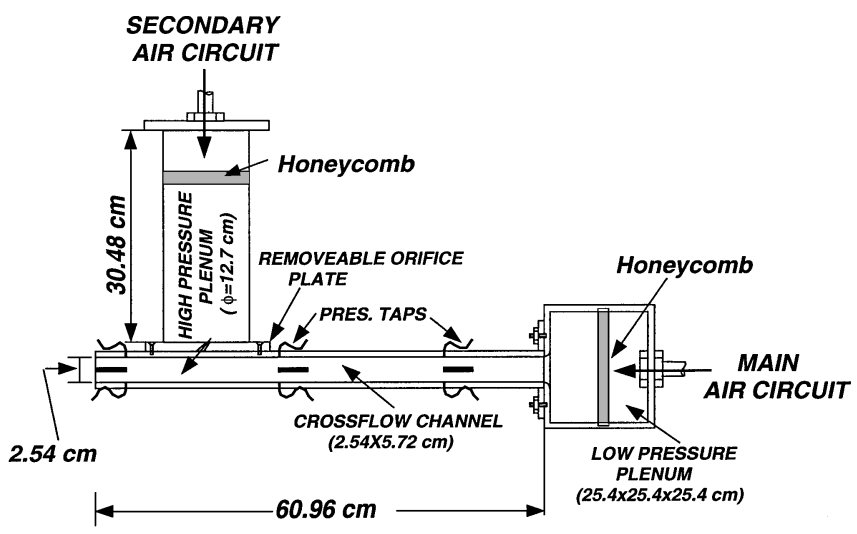

(a) Test Setup

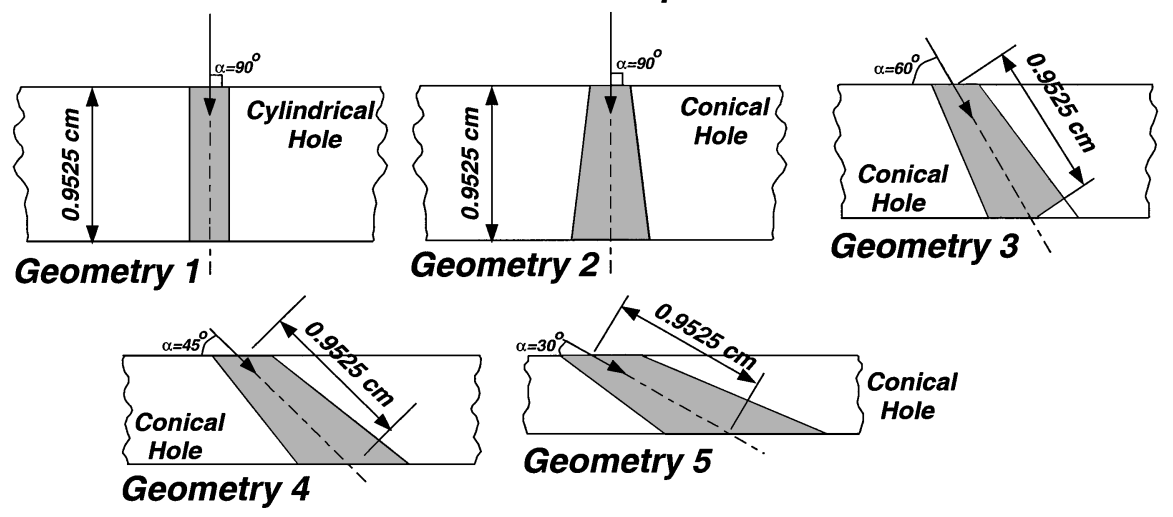

(b) Hole Geometry on Removeable Plate

FIGURE 1

Schematics of the apparatus. 


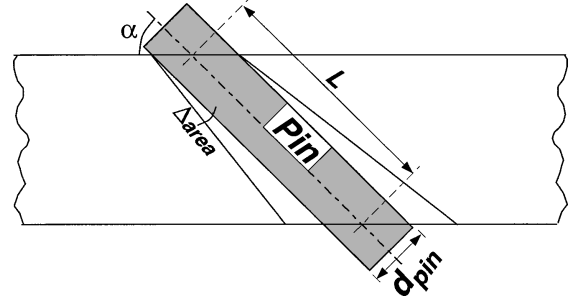

FIGURE 2

Pinning of the conical holes.

ends to provide a mounting surface for 2 end-plates. The orifice plate was mounted on the end of high-pressure plenum that interfaced with the cross-flow channel and the opposite end-plate accommodated the inlet piping. A honeycomb flow straightener was installed inside the high-pressure plenum. Three pressure taps and a thermocouple measured the plenum total pressure and temperature upstream of the orifice. Pressure measurements in the high-pressure plenum were taken sufficiently far from the hole inlet that there were no perceptible velocity head. Typical air inlet temperature was about $22^{\circ} \mathrm{C}$ and the pressure in the high-pressure plenum was varied from about $103 \mathrm{Kpa}$ to a maximum of about $735 \mathrm{Kpa}$. The circular orifice plate with the desired orifice geometry at its center was mounted on the end flange of the high-pressure plenum and interfaced flush with the cross-flow channel wall. Five orifice plates with conical holes, shown in Figure 1b, were tested. At the center of each plate the desired hole geometry was drilled. The inclination angle $\alpha$, shown in Figure 1b, is the angle between the axis perpendicular to the orifice plate plane and the hole longitudinal axis. The conical holes were drilled with a conical end mill ( $7^{\circ}$ half-angle) for 4 values of $\alpha=0,30^{\circ}, 45^{\circ}$, and $60^{\circ}$. A cylindrical hole which served as a baseline case was drilled straight through at $\alpha=90^{\circ}$. The sharpness of the hole edges were what came out of the CNC machine and no attempt was made to round them off. Although the nominal inlet diameter for all holes (conical or cylindrical) was set to $2.54 \mathrm{~mm}$, they were, however, pinned after machining as illustrated in Figure 2. The pin diameter measurements were used in the data reduction procedure. Table I shows the finished geometry of all tested holes. To have the same hole length, $L$, for all holes, the orifice plate thickness decreased as the hole angle, $\alpha$, increased.

TABLE 1

Finished Hole Geometries

\begin{tabular}{|c|c|c|c|c|c|}
\hline Geometry & Type & $\begin{array}{c}\alpha \\
\text { Degrees }\end{array}$ & $\begin{array}{c}\mathrm{d}_{\text {pin }} \\
\text { (pinned) } \\
\mathrm{mm}\end{array}$ & $\begin{array}{c}\mathrm{L} \\
\mathrm{cm}\end{array}$ & $\mathrm{L} / \mathrm{d}_{\text {pin }}$ \\
\hline 1 & Cylindrical & 90 & 2.57 & 0.9525 & 3.71 \\
\hline 2 & Conical & 90 & 2.69 & 0.9525 & 3.54 \\
\hline 3 & Conical & 60 & 2.84 & 0.9525 & 3.35 \\
\hline 4 & Conical & 45 & 3.048 & 0.9525 & 3.125 \\
\hline 5 & Conical & 30 & 3.76 & 0.9525 & 2.54 \\
\hline
\end{tabular}

The 61-cm long aluminum cross-flow channel with a crosssection of $5.71 \mathrm{~cm}$ by $2.54 \mathrm{~cm}$ was fed by its own separate $22.86-\mathrm{cm} \times 22.86-\mathrm{cm} \times 22.86-\mathrm{cm}$ aluminum plenum equipped with a honeycomb flow straightener, a bell-mouth opening to the cross-flow channel, 3 pressure taps and 2 thermocouples to measure the incoming air flow conditions. A circular opening on its wider wall, $50.8 \mathrm{~cm}$ from its inlet, allowed the orifice plate to interface with the cross-flow channel. A flange with the exact symmetric hole pattern as those on the orifice plate allowed a flush attachment of the orifice plate to the cross-flow channel wall. It furthermore allowed the rotation of the orifice plate and measurement of the discharge coefficient when the conical hole angle with the cross-flow, $\beta$, was $0^{\circ}, 45^{\circ}, 90^{\circ}, 135^{\circ}$, and $180^{\circ}$ (Figure 3). Four static pressure taps, mounted on the four walls of the cross-flow channel, on a plane immediately upstream of the hole exit in the cross-flow channel measured the static pressure at the hole exit. Two critical venturimeters measured the air mass flow rate through the orifice and cross-flow channel separately. A contact micromanometer with an accuracy of $0.025 \mathrm{~mm}$ of water column as well as a series of oil and mercury manometers measured the pressures at different locations.

\section{PROCEDURE}

The isentropic mass flow rate was calculated assuming a onedimensional expansion from the upstream plenum total pressure to the downstream static pressure. For unchoked flow cases, the governing equation is:

$m_{\text {isen }}=P_{o}\left(\frac{P_{s}}{P_{o}}\right)^{\left(\frac{\gamma+1}{2 \gamma}\right)} \sqrt{\frac{2 g_{c} \gamma}{(\gamma-1) R T_{0}}}\left[\left(\frac{P_{o}}{P_{s}}\right)^{\left(\frac{\gamma-1}{\gamma}\right)}-1\right]^{\frac{1}{2}}\left(\frac{\pi}{4}\right) d_{\text {pin }}^{2}$

For the choked pressure ratios and higher tests cases, a sonic flow was assumed at the minimum area and the isentropic mass flow rate was calculated accordingly. The use of minimum pinned area (Figure 2) for the isentropic flow calculation was, (1) due to a common practice in gas turbine industry, (2) $m_{\text {isen }}$ merely plays a normalizing role in the definition of the discharge coefficient, and (3) the accuracy and ease of minimum area measurement. Since the ultimate purpose of the user of the discharge coefficient is to calculate the actual mass flow rate, the

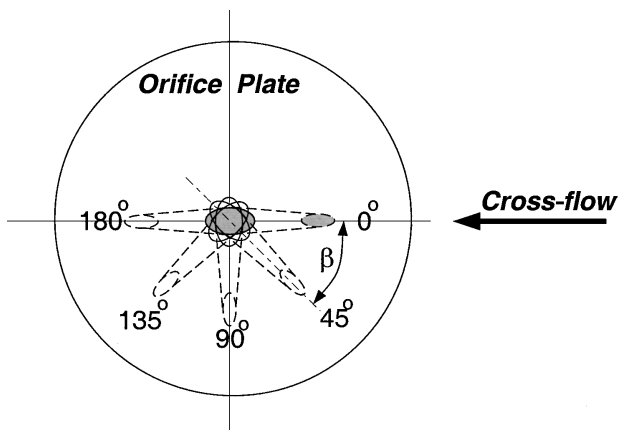

FIGURE 3

Conical hole exit angle with cross-flow. 
manner in which $m_{\text {isen }}$ is calculated does not matter. The selected choice of minimum area, however, can result in discharge coefficients greater than unity for the highly angled diffusion holes for which the effective flow area is greater than the minimum pinned area. These cases will be discussed shortly. Experimental uncertainty in discharge coefficient, following the method of Kline and McClintock (1953), was determined to be $\pm 6 \%$.

\section{RESULTS AND DISCUSSION}

Figure 4 shows the variation of the discharge coefficient for the straight-through cylindrical hole geometry with the ratio of upstream plenum total pressure to the downstream static pressure. This geometry served as a baseline to which other geometries were compared. The no cross-flow discharge coefficient averages about 0.855 which is about $3 \%$ higher than the 0.83 value reported for a sharp-edged orifice. This difference is attributed to a very small inlet corner radius caused by the "breaking" of the edge of the machined inlet corner of the orifice. Parker and Kercher (1991) reported on the strong influence of the inlet corner radius on the discharge coefficient. According to these authors, the reported value of 0.855 for the discharge coefficient corresponds to an $\mathrm{r} / \mathrm{d}$ of about 0.025 , i.e., a corner radius of about $0.0635 \mathrm{~mm}$ in this case. The slight effect of downstream crossflow can only be seen at smaller pressure ratios. For pressure ratios of 2 and higher, the difference in the discharge coefficient with and without the cross-flow is within the range of experimental uncertainties.

Figure 5 shows the variation of the discharge coefficient with the pressure ratio for the $90^{\circ}$ conical hole (Figure $1 \mathrm{~b}$,

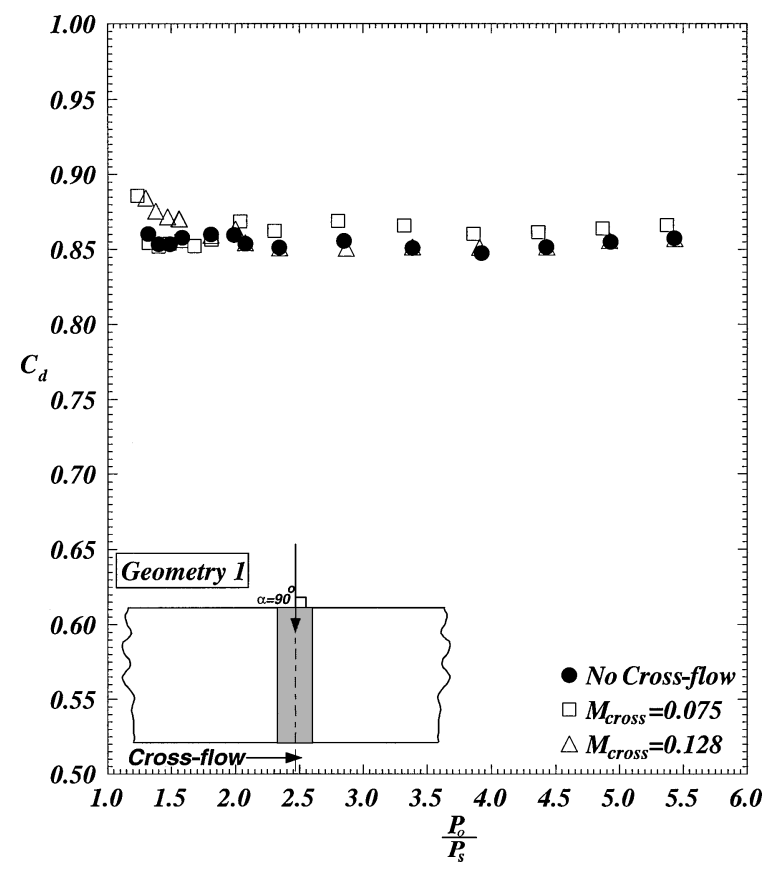

FIGURE 4

Variation of discharge coefficient with pressure ratio for the $90^{\circ}$ cylindrical hole.

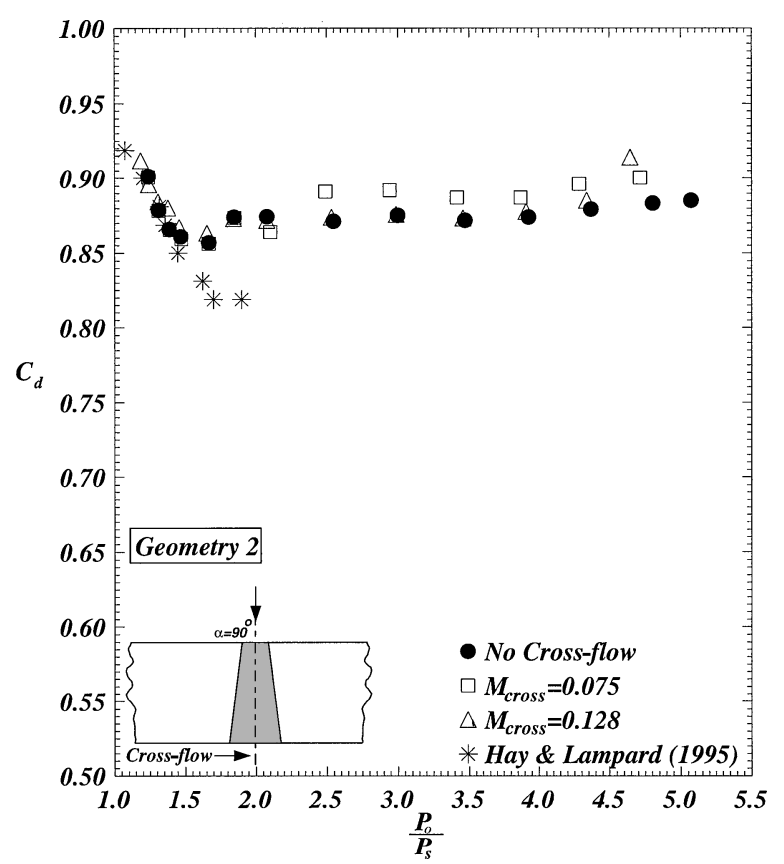

FIGURE 5

Variation of discharge coefficient with pressure ratio for the $90^{\circ}$ conical hole.

Geometry 2). Hay and Lampard's (1995) results for a $90^{\circ}$ flared hole of $\mathrm{L} / \mathrm{d}=4\left(L=12 \mathrm{~mm}, d=3 \mathrm{~mm}, 25^{\circ}\right.$ flare, $7.5^{\circ}$ layback) with no cross-flow are shown for comparison. Although the hole geometries are not identical, good agreement is observed at lower pressure ratios. At pressure ratios beyond 1.5, the $90^{\circ}$ conical hole appears to display a higher discharge coefficient than the $90^{\circ}$ flared hole.

Figures $6 \mathrm{a}$ and $6 \mathrm{~b}$ show the variation of the discharge coefficient with pressure ratio for the $60^{\circ}$ conical hole (Figure $1 \mathrm{~b}$, Geometry 3 ) and 2 cross-flow Mach numbers. In each case, the conical hole projection angle, $\beta$, shown in Figure 3, is varied from $0^{\circ}$ to $180^{\circ}$. This was accomplished by the clockwise rotation of the orifice plate at a $45^{\circ}$ increment. In Figure $6 \mathrm{a}$, at the lower range of the pressure ratios $(<2)$, the $0^{\circ}$-projection angle, corresponding to the case where the cross-flow and the jet issued out of the conical hole are in the same direction, produced the highest discharge coefficient. For the same pressure ratio range, the $180^{\circ}$-projection angle, corresponding to the case where the cross-flow and the jet issued out of the conical hole are in opposite directions, produced the lowest discharge coefficient. At higher pressure ratios, however, results of different $\beta$ angles were close to each other with differences that were within the range of experimental uncertainty thus a definite conclusion as to which configuration is superior could not be made. It should be noted that these tests were performed for a relatively low cross-flow Mach number and only at lower jet pressure ratios the cross-flow could affect the jet flow with a relatively low momentum.

Figures $7 \mathrm{a}$ and $7 \mathrm{~b}$ show the variation of the discharge coefficient with the pressure ratio for the $45^{\circ}$ conical hole (Figure $1 \mathrm{~b}$, 


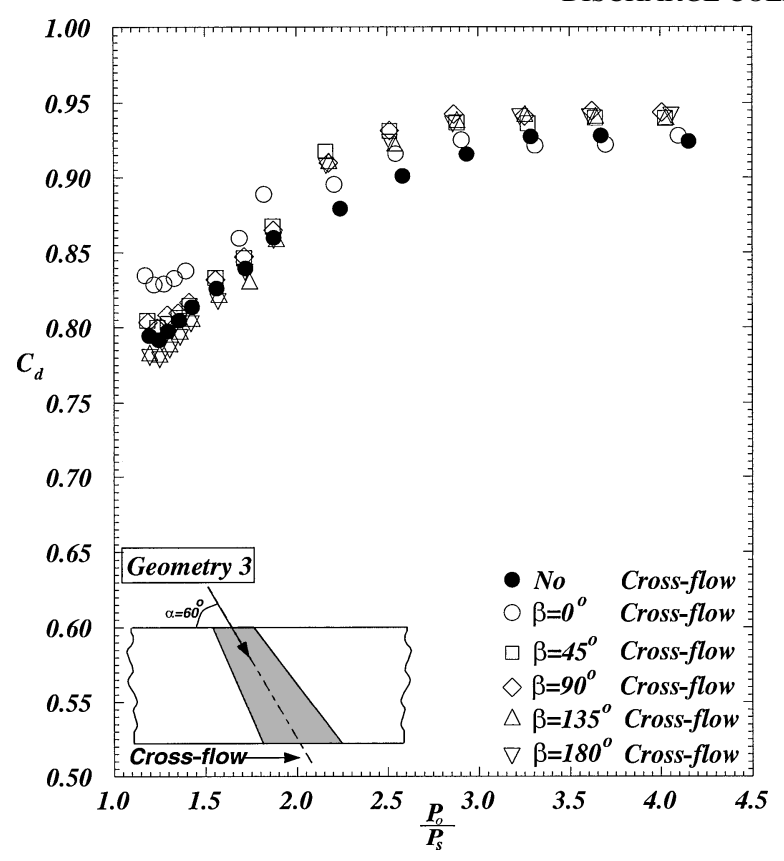

FIGURE 6a

Variation of discharge coefficient with pressure ratio for $\alpha=60^{\circ}$ conical hole at different $\beta$ angles, $M_{\text {cross }}=0.075$.

Geometry 4) and for 2 cross-flow Mach numbers. Again the conical hole projection angle, $\beta$, varied from $0^{\circ}$ to $180^{\circ}$. For the case of higher cross-flow Mach number (Figure 7b) and at the lower range of the pressure ratios $(<2)$, the effects of $\beta$ angle are more pronounced. The $180^{\circ}$-projection angle produced a lower dis-

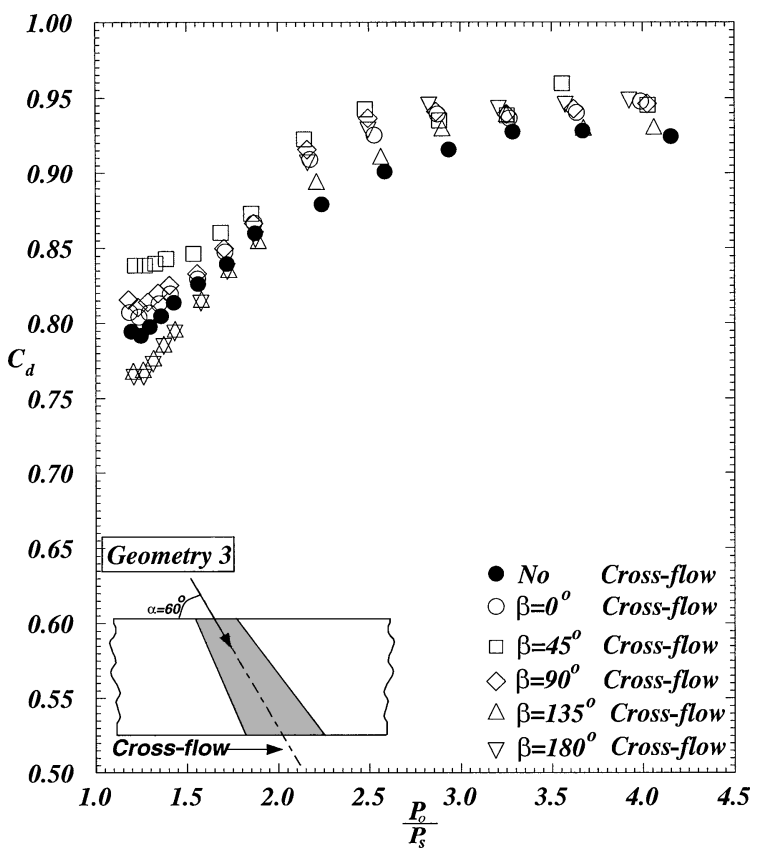

FIGURE 6b

Variation of discharge coefficient with pressure ratio for $\alpha=60^{\circ}$ conical hole at different $\beta$ angles, $M_{\text {cross }}=0.128$.

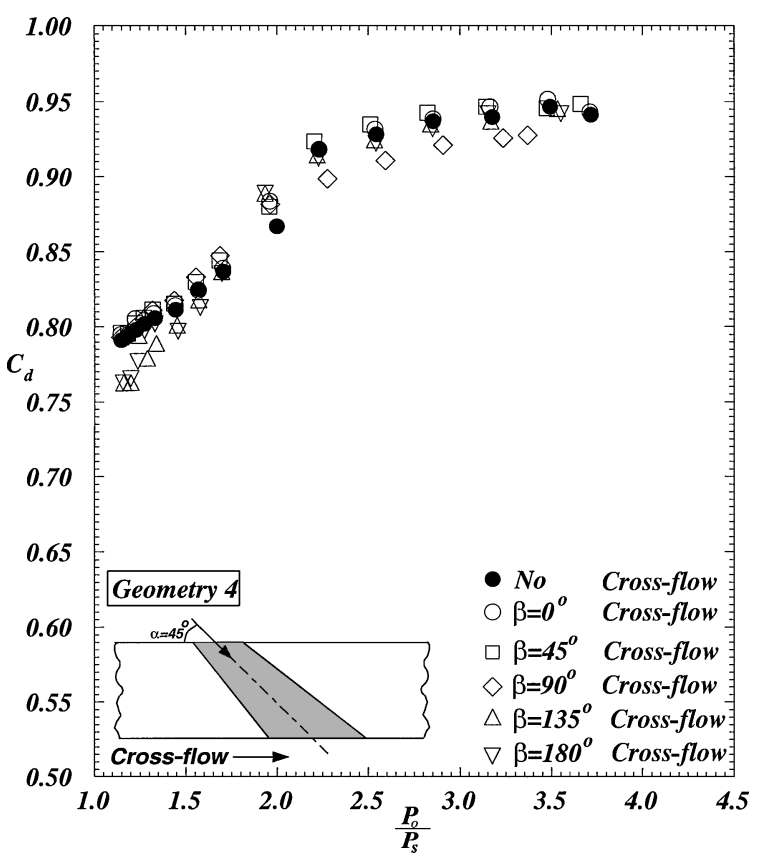

FIGURE 7a

Variation of discharge coefficient with pressure ratio for $\alpha=45^{\circ}$ conical hole at different $\beta$ angles, $M_{\text {cross }}=0.075$.

charge coefficient for the entire range of pressure ratio. As the jet was less and less opposed to the cross-flow, the discharge coefficient increased. For the case of lower cross-flow Mach number (Figure 7a), discharge coefficient, especially at higher pressure ratios, was insensitive to the $\beta$ angle.

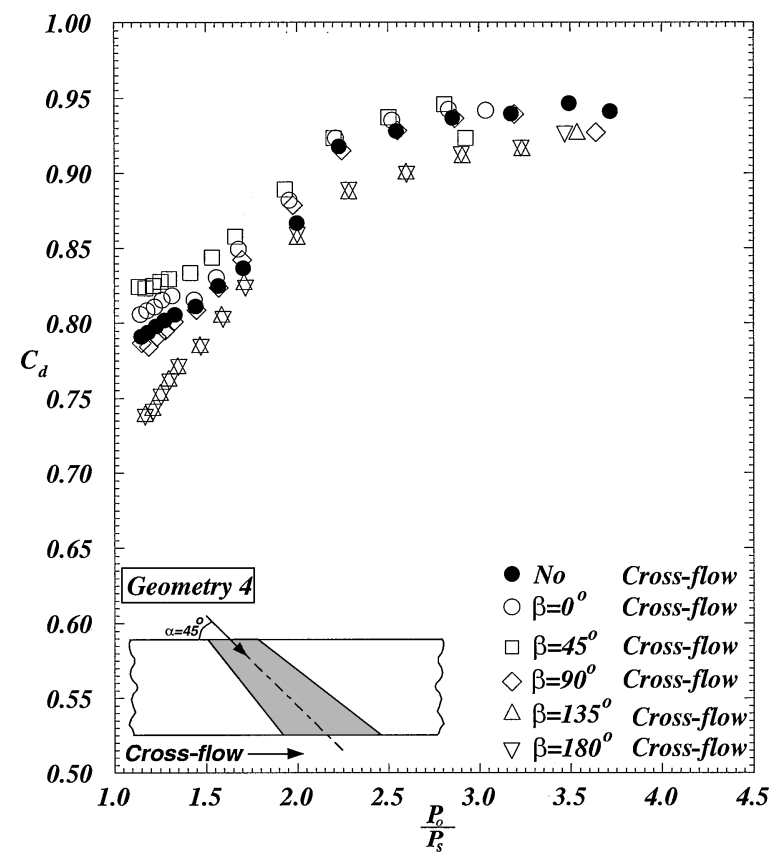

FIGURE 7b

Variation of discharge coefficient with pressure ratio for $\alpha=45^{\circ}$ conical hole at different $\beta$ angles, $M_{\text {cross }}=0.128$. 


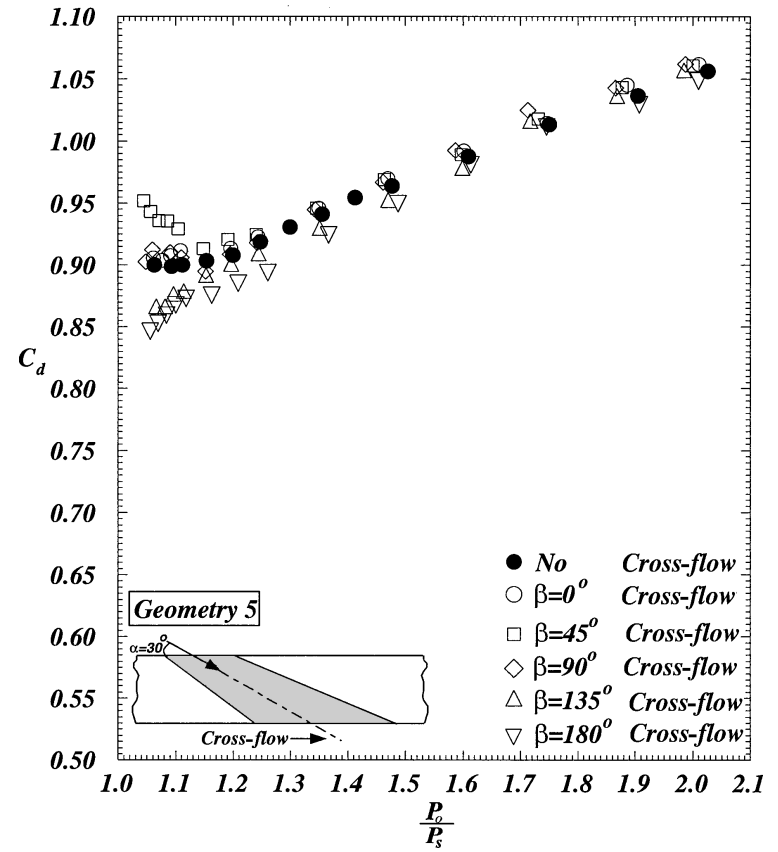

FIGURE 8a

Variation of discharge coefficient with pressure ratio for $\alpha=30^{\circ}$ conical hole at different $\beta$ angles, $M_{\text {cross }}=0.075$.

Figures $8 \mathrm{a}$ and $8 \mathrm{~b}$ show the variation of the discharge coefficient with the pressure ratio for yet a lower conical hole angle of $30^{\circ}$ (Figure 1b, Geometry 5) and for 2 cross-flow Mach numbers. Again, the conical hole projection angle, $\beta$, varied from $0^{\circ}$ to $180^{\circ}$. Several observations can be made. The discharge

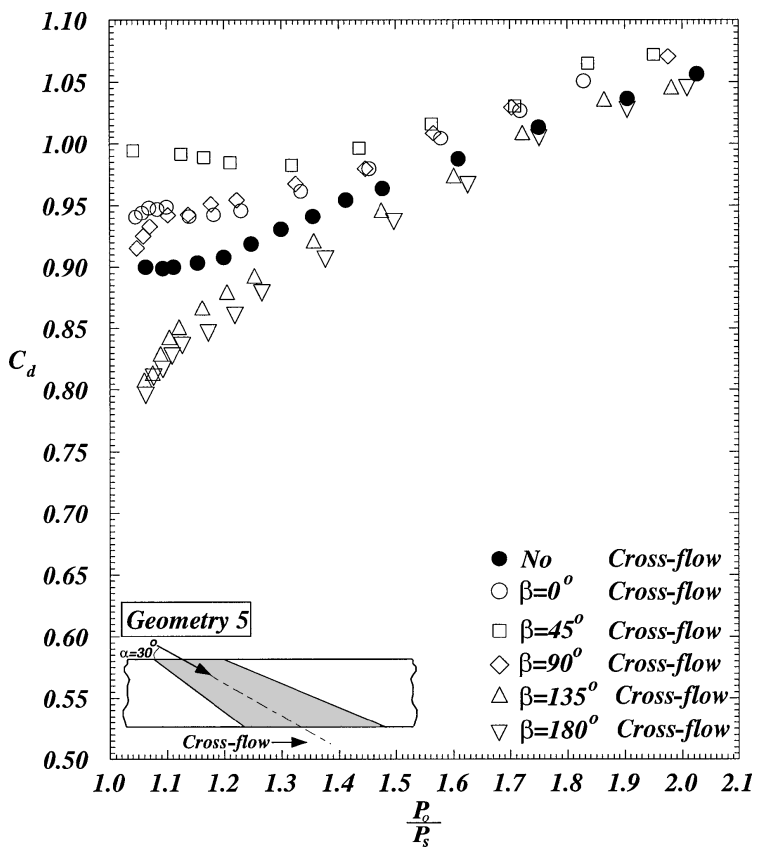

FIGURE 8b

Variation of discharge coefficient with pressure ratio for $\alpha=30^{\circ}$ conical hole at different $\beta$ angles, $M_{\text {cross }}=0.128$.

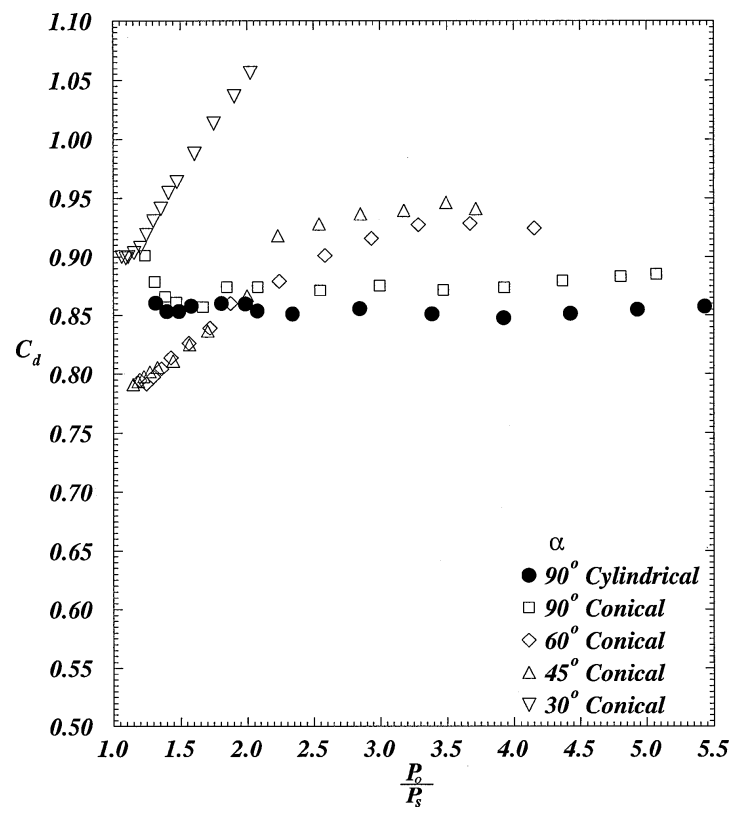

FIGURE 9

A comparison of discharge coefficients for different geometries with no cross-flow.

coefficient at higher pressure ratios is greater than one. This is an indication that the effective flow area is greater than the minimum pinned area. In other words, the calculated isentropic mass flow rate by which the actual mass flow rate was normalized is based on the minimum pinned area while the hole half angle (Figure 1b, Geometry 5) and the inclination angle, $\alpha$, allows a larger opening ( $\triangle$ area in Figure 2), thus a larger physical area than pinned area. As a result, the isentropic flow in this case is underestimated for the smaller pinned diameter thus the discharge coefficient is greater than one. Gritsch et al. (1997) have also reported discharge coefficients greater than one for the fanshaped and laidback fan-shaped holes. This behavior, however, does not change the usefulness of the discharge coefficient for the user who applies the same procedure for the calculation of mass flow rate through shaped holes. For example, in the gas turbine industry it is a common practice to pin the shaped film holes and use the appropriate discharge coefficient to calculate the coolant mass flow. Any other procedure such as attempting to estimate the effective flow area or a throat area, realizing the complex flow pattern through such shaped holes, is neither as accurate nor as inexpensive. For the same amount of available orifice air in the secondary circuit and nearly the same pinned area, the pressure ratio across the $30^{\circ}$ angle hole did not go beyond 2.05 while for other hole geometries the upper limit for the pressure ratio was almost twice as much. This is another indication that the effective flow area for this low angle hole geometry is larger than the hole geometries 1 through 4 . Effects of cross-flow angle are more pronounced for the case of high cross-flow Mach numbers. Again, the case of opposing crossflow $\left(\beta=180^{\circ}\right)$ produced the lowest discharge coefficient for both cross-flow Mach numbers. 


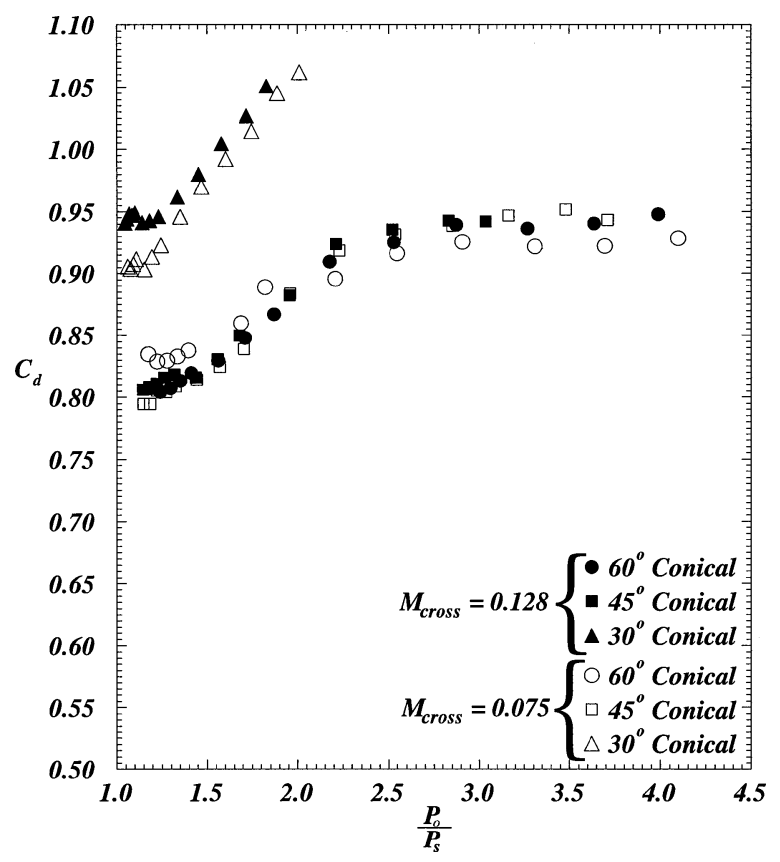

FIGURE 10

A comparison of discharge coefficients for different geometries with $\beta=0^{\circ}$ cross-flow.

Figure 9 shows the comparison of the discharge coefficients for the five hole geometries with no cross-flow. It is observed that for the same amount of maximum available secondary air and almost the same pinned area, the maximum pressure ratio

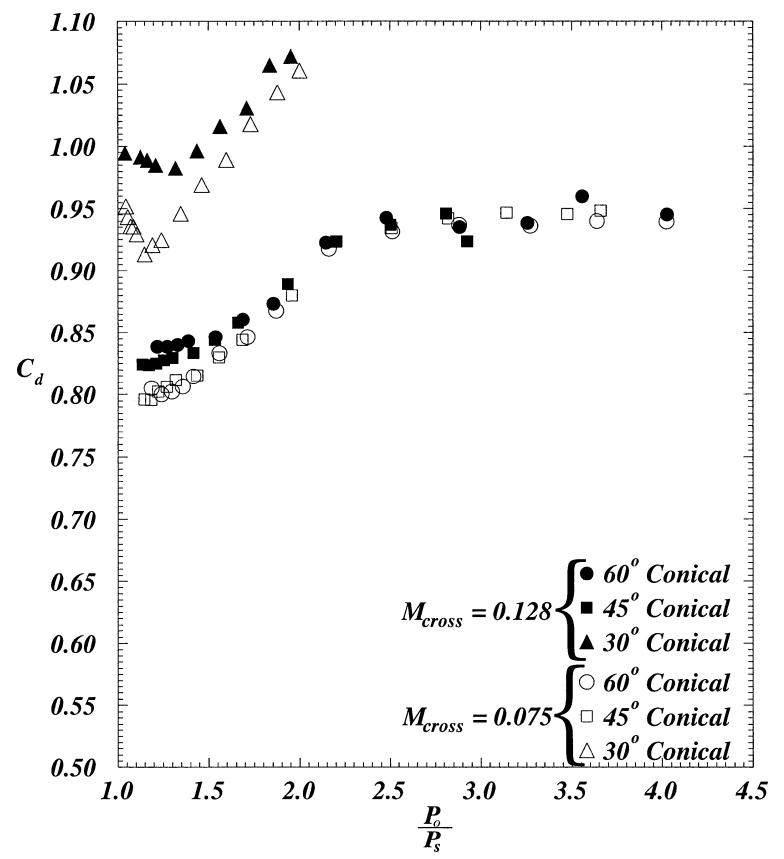

FIGURE 11

A comparison of discharge coefficients for different geometries with $\beta=45^{\circ}$ cross-flow.

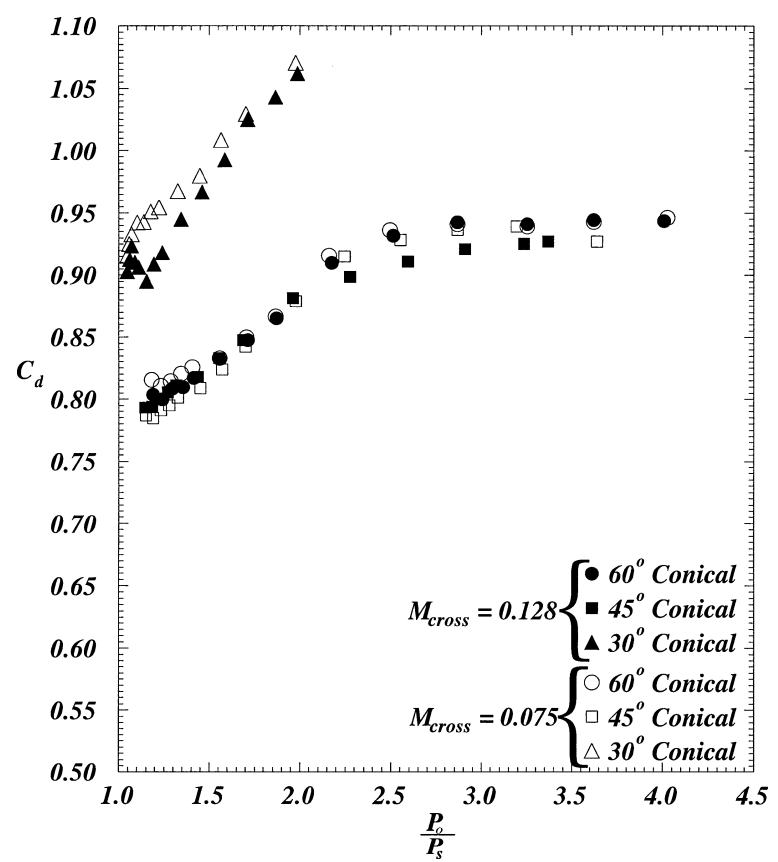

FIGURE 12

A comparison of discharge coefficients for different geometries with $\beta=90^{\circ}$ cross-flow.

limit is decreased as the hole compound angle decreased, i.e., a reduction from 5.54 for the straight-through cylindrical hole to 2.05 for the $30^{\circ}$ hole. That observation also explains the increase in the discharge coefficient at higher pressure ratios as

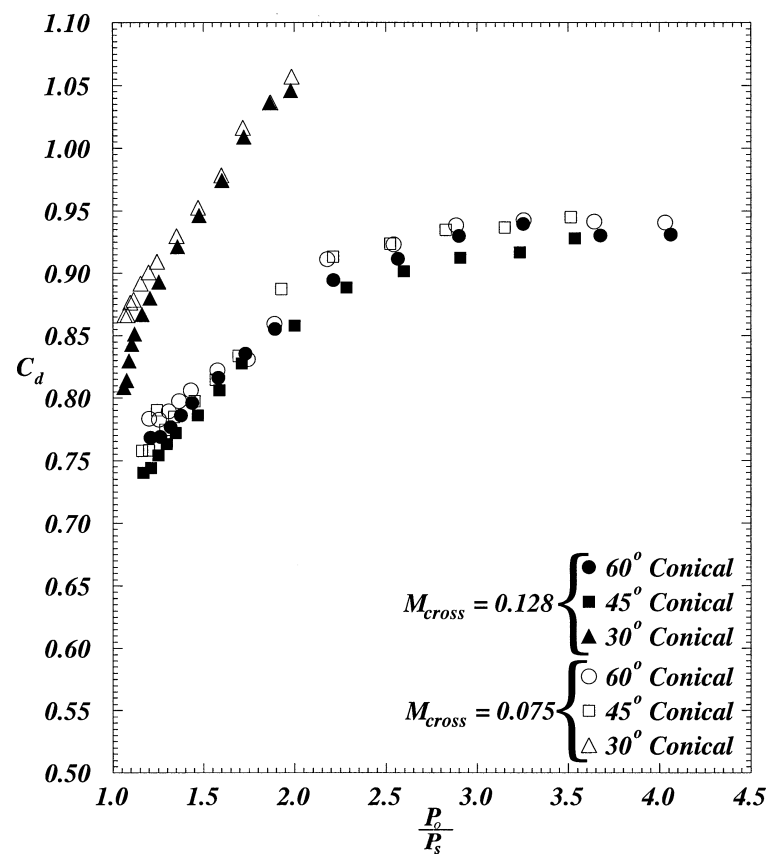

FIGURE 13

A comparison of discharge coefficients for different geometries with $\beta=135^{\circ}$ cross-flow. 
the hole angle, $\alpha$, decreases and $\Delta$ area increases (Figure 2). Lower discharge coefficients at low pressure ratios for the $45^{\circ}$ and $60^{\circ}$ conical holes can be attributed to the formation of an air bubble in those passages due to flow separation which reduces the effective flow area (Kohli and Thole, 1998). The remarkable change in discharge coefficient for the $30^{\circ}$ inclination angle is due to nonlinear changes in hole geometry and its effects on flow pattern as the inclination angle varies. For example, as the conical hole is rotated from an inclination angle $(\alpha)$ of $90^{\circ}$ to $60^{\circ}, 45^{\circ}$, and $30^{\circ}$, the stepwise increase in exit area (projected on exit surface) is about $16 \%, 24 \%$, and $48 \%$, respectively. These percentages will be $16 \%, 45 \%$, and $115 \%$, when the $60^{\circ}, 45^{\circ}$, and $30^{\circ}$ holes are compared with the $90^{\circ}$ hole, i.e., the exit area alone varies almost as $1 / \sin \alpha$. The discharge coefficient for the conical hole at $\alpha=90^{\circ}$ is about 3\% higher than that for the cylindrical hole at the same angle.

Figures 10 through 14 compare the discharge coefficients of the three angled conical hole geometries for five cross-flow angles. A comparison between the results of the two extreme cases of $\beta=0^{\circ}$ (cross-flow and projected orifice flow in the same direction) and those of $\beta=180^{\circ}$ (cross-flow and projected orifice flow in opposite directions) shows that the high Mach number cross-flow increases the discharge coefficient when it is in the direction of the orifice flow and decreases the discharge coefficient when it is in the opposite direction of the orifice flow. This behavior can be explained by the reduction of static pressure at the orifice exit in the former case and the increase of static pressure at the orifice exit in the latter case. As the

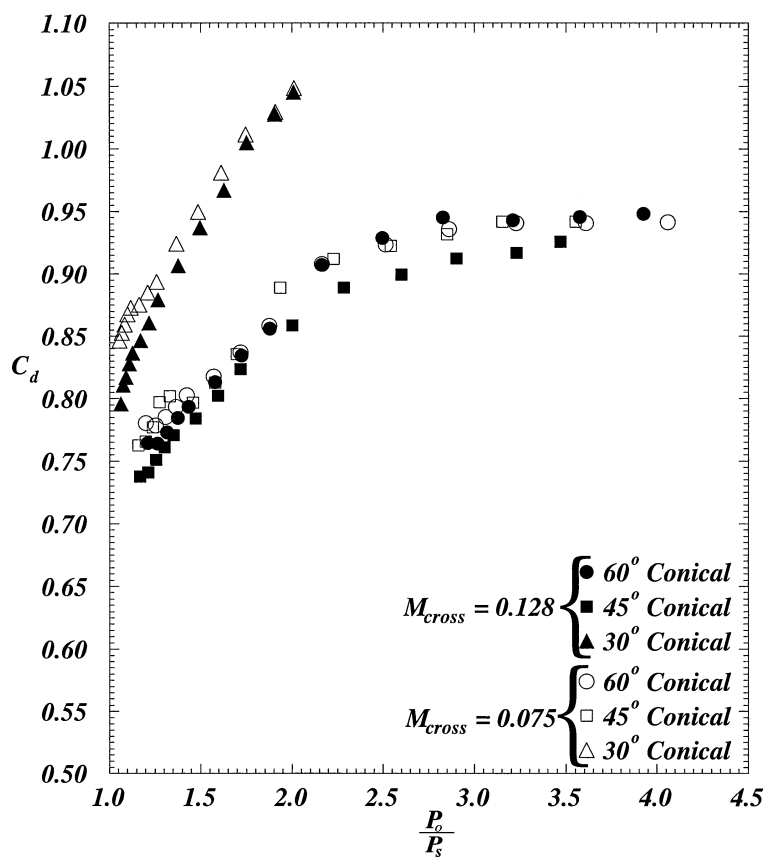

FIGURE 14

A comparison of discharge coefficients for different geometries with $\beta=180^{\circ}$ cross-flow. angle $\beta$ increases beyond $45^{\circ}$, the solid symbols representing the high Mach number cross-flow shift below the hollow symbols representing the low Mach number cross-flow.

\section{CONCLUSIONS}

Discharge coefficients are reported for a conical hole of $7^{\circ}$ half-angle at four inclination angles with and without the presence of cross-flow. A straight-through cylindrical hole is also tested under the same flow conditions, the results of which are compared with those of the conical holes. The following is therefore concluded:

(a) At higher pressure ratios, conical holes have a higher discharge coefficient than that of cylindrical holes.

(b) At higher pressure ratios, as the inclination angle decreases, the discharge coefficient increases.

(c) For the tested cross-flow Mach numbers, the overall effect of the cross-flow is a slight increase in discharge coefficient when it is in the same direction as that of the orifice flow and a slight decrease in discharge coefficient when it is in the opposite direction of the orifice flow.

\section{NOMENCLATURE}

$C_{d} \quad$ discharge coefficient, $m_{\text {actual }} / m_{\text {isen }}$

$d_{\text {pin }} \quad$ pinned diameter (Figure 2)

$g_{c} \quad$ proportionality constant in Newton's 2nd law

$L \quad$ hole length

$M_{\text {cross }}$ cross-flow Mach number

$m_{\text {actual }}$ actual measured mass flow rate

$m_{\text {isen }} \quad$ isentropic mass flow rate based on the pinned minimum diameter

$T_{o} \quad$ upstream plenum total temperature

$P_{o} \quad$ upstream plenum total pressure

$P_{s} \quad$ downstream static pressure

$r \quad$ hole inlet corner radius

$R \quad$ gas constant

$\gamma \quad$ specific heat ratio, $c_{p} / c_{v}$

$\alpha \quad$ hole axis angle with the exit plane (Figure 1)

$\beta \quad$ hole projection angle with the cross-flow (Figure 3)

\section{REFERENCES}

Burd, S. W., and Simon, T. W. 1998. Measurement of Discharge Coefficients in Film Cooling, ASME Paper 98-GT-9.

Gritsch, M., Schulz, A., and Wittig, S. 1997. Discharge Coefficient Measurements of Film Cooling Holes with Expanded Exits, ASME Paper 97-GT-165.

Hay, N., and Lampard, D. 1995. The Discharge Coefficient of Flared Film Cooling Holes, ASME Paper 96-GT-492.

Hay, N., and Spencer, A. 1992. Discharge coefficients of cooling holes with radiused and chamfered inlets. J. Turbomachinery 114:701706.

Hay, N., Lampard, D., and Benmansour, S. 1983. Effect of cross-flow on the discharge coefficient of film cooling holes. J. Eng. for Power 105:243-248. 
Hay, N., Lampard, D., and Khalid, A. 1994. The Coefficient of Discharge of 30 Degree Inclined Film Cooling Holes with Rounded Entries and Exits, ASME Paper 94-GT-180.

Hippensteele, S. A., and Cochran, R. P. 1980. Effect of Hole Geometry and Electric-Discharge Machining (EDM) on Airflow Rates Through Small-Diameter Holes in Turbine Blade Material, NASA TP 1716.

Kline, S. J., and McClintock, F. A. 1953. Describing uncertainty in single-sample experiments. Mechanical Engineering 75:3-8.

Kohli, A., and Thole, K. 1998. Entrance Effects on Diffused FilmCooling Holes, ASME Paper 98-GT-402.
Meitner, P. L., and Hippensteele, S. A. 1977. Experimental Flow Coefficients of a Full-Coverage Film-Cooled-Vane Chamber, NASA TP 1036.

Parker, D. M., and Kercher, D. M. 1991. An enhanced method to compute the compressible discharge coefficient of thin and long orifices with inlet corner radiusing. Heat Transfer in Gas Turbine Engines, ASME HTD 188:53-63.

Rohde, J. E., Richards, H. T., and Metger, G. W. 1969. Discharge Coefficients for Thick Plate Orifices With Approach Flow Perpendicular and Inclined to the Orifice Axis, NASA TN D-5467. 

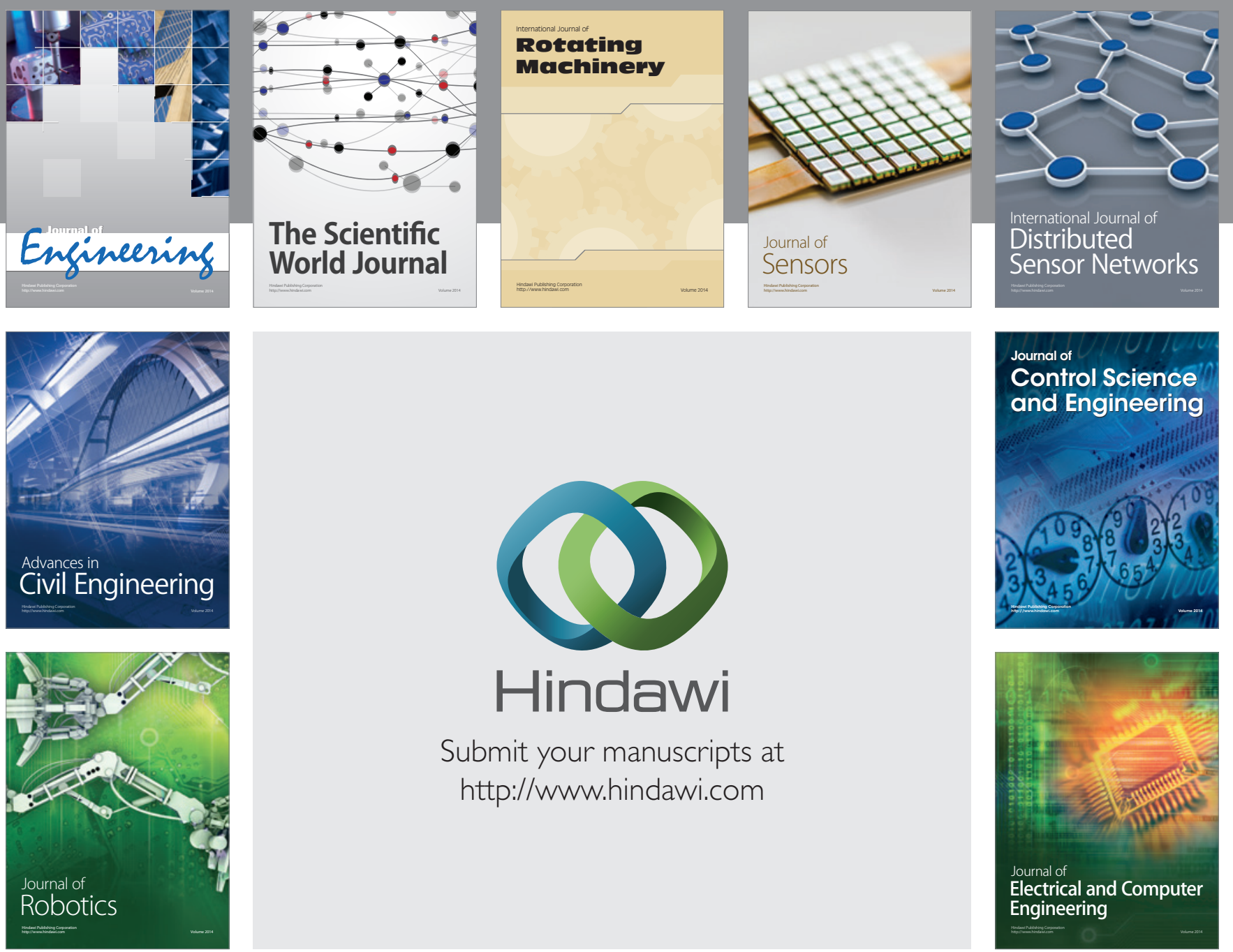

Submit your manuscripts at

http://www.hindawi.com
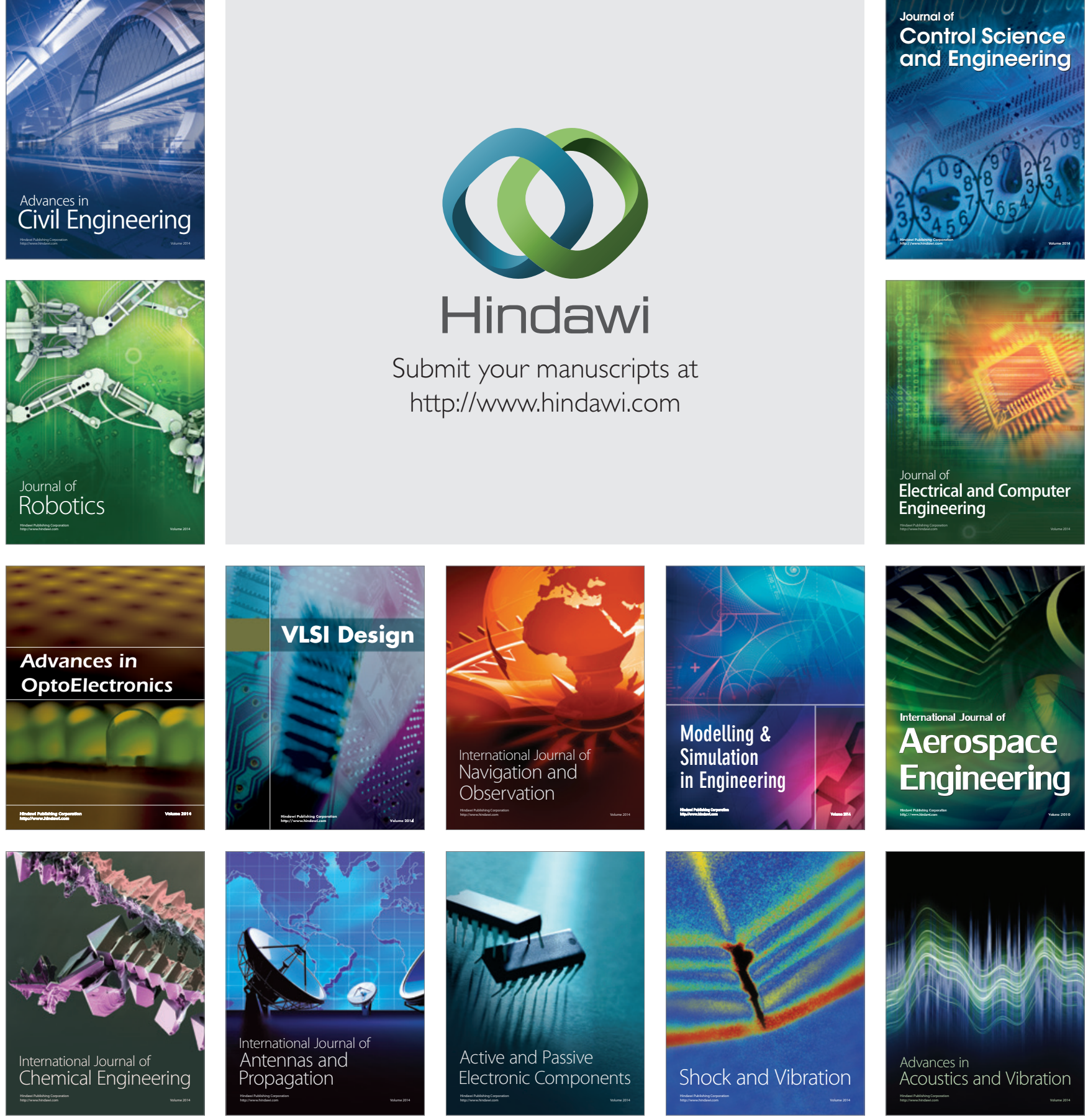